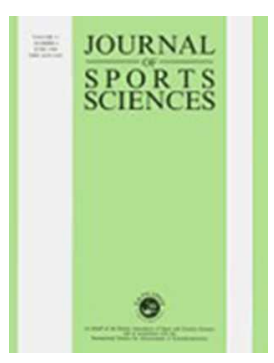

\title{
Validity of self-reported sedentary time differs between Australian rural men engaged in office and farming occupations
}

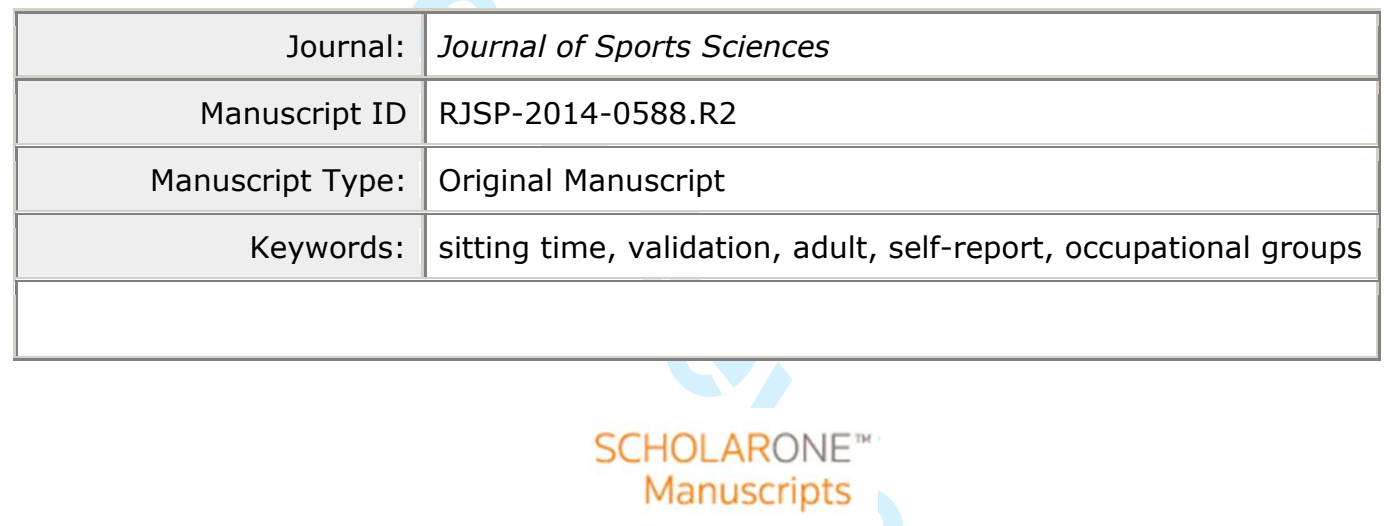


Introduction

There is accumulating evidence for the detrimental health effects of prolonged and uninterrupted sitting, including type 2 diabetes and biomarkers of cardio-metabolic diseases (Healy et al., 2008). Research attention has focused on the workplace as a setting within which daily sitting behaviours are largely determined (Carnethon et al., 2009), motivated by prospective evidence of associations between occupational sitting and type 2 diabetes (van Uffelen et al., 2010).

State and national surveys in Australia consistently report poorer overall health among rural compared with urban adults (Australian Institute of Health and Welfare, 2010). To help narrow this health disparity, patterns of occupational sitting among rural adults warrant attention as a basis for designing and evaluating practices and initiatives that are tailored to different workplace settings. The measurement of sitting is in its infancy, with self-report and objective measures becoming increasingly available. Self-reported sitting is usually assessed with simple questionnaires, either self- or interviewer-administered, while objective measurement is achieved using inclinometers or inferred from established thresholds in accelerometry data.

Self-report of health-related behaviours offers the advantages of low cost and convenience of administration over more expensive and sometimes burdensome objective methods (Dollman et al., 2009). Notably, the validity of selfreported sitting has been reported to vary according to the relative proportions of sitting and standing undertaken in the workplace, with higher validity coefficients observed among desk-based compared with more active occupations (Clark et al., 2011). The aim of this study was to validate questions on sitting behaviours from the South Australian Physical Activity Survey (SAPAC; Gill, Fullerton \& Taylor, 2008), an on-going physical activity monitoring survey of adult South Australians, using inclinometer-derived postural information (sitting/lying and standing) as the criterion, 
among rural male office workers and male farmers who would be expected to differ markedly in terms of occupational sitting, standing and ambulation. The study was conducted in the Riverland region of South Australia where approximately $57 \%$ of the population aged 16 years and over do not meet physical activity guidelines of 150 minutes of moderate to vigorous physical activity per week, the highest level of inactivity among all South Australian regions (Population Research and Outcome Studies, 2010). The analysis included total sedentary time (sitting/lying) as well as the number of breaks in sitting time throughout the day.

Methods

The sample

An Accessibility/Remoteness Index of Australia (ARIA) classifies rural regions as inner regional, outer regional, remote and very remote, using an index derived from quantified access to goods, services and opportunities for social interaction; The Riverland is classified as 'outer regional' or 'moderately accessible' (Australian Bureau of Statistics, 2006b). Participants were recruited via personal contacts, local email lists, print and electronic media. Men were included if they were $30-65$ years of age and employed full time as an office worker or farmer. The study excluded women as few women work as full time farmers and those who do undertake active farming tasks often combine these with domestic roles. The analyses reported here are secondary to a study that compared sitting behaviours between farmers and office workers (Pontt, Rowlands \& Dollman, 2014). The sample size of 30 farmers and 30 office workers was determined on the basis of this comparison.

Office-based occupations were defined as employment in clerical, administrative or management sectors that are predominantly based in an office. 
Farming occupations included farming sectors typical of dominant primary industries in the region i.e. grain and livestock, grape growing and citrus production (Australian Bureau of Statistics, 2006a). Ethics approval was obtained from the Human Research Ethics Committee of the University of South Australia.

Procedure

Data were collected over six weeks from mid-August 2012 to mid-September 2012, the maintenance phase of the farming calendar between sowing and harvesting. Each participant wore an activPAL ${ }^{\circledR}$ monitor (PAL technologies Ltd, Glasgow, UK) for three consecutive full working days, previously reported as sufficient to account for day-to-day variability and thereby characterise habitual physical activity among adults (Tudor-Locke et al., 2005). At an introductory meeting in a convenient community location, occupation was confirmed, demographic data were collected, height and weight were measured, and the $\operatorname{activPAL}{ }^{\circledR}$ was attached. Thereafter participants were required to wear the monitor continuously for three working days, including when showering/bathing, swimming and sleeping. A log sheet was used to record if the monitor was removed and for what reason, as well as times of going to and getting out of bed. Self-reported sedentary behaviours were recorded in a one-on-one interview when participants returned the activPAL ${ }^{\circledR}$ on the day following the three day monitoring period.

\section{Measurement of sedentary time}

The activPAL ${ }^{\circledR}$ is a small, lightweight $(15 \mathrm{~g})$ uniaxial accelerometer. It was placed in a waterproof finger cot and attached to the mid-anterior right thigh using a porous hypoallergenic tape. Based on postures inferred from the thigh position, activity is classified into episodes of sitting/lying, standing and walking (Grant, Ryan, 
Tigbe, \& Granat, 2006). The number of sit-to-stand transitions and step counts are also recorded. ActivPAL ${ }^{\circledR}$ data are summed over a 15-second epoch with a sampling rate of 10 Hertz. Previous studies have reported 96\% (Grant et al. 2006) and 100\% (Hart, McClain, \& Tudor-Locke, 2011) agreement between postures recorded with activPAL ${ }^{\circledR}$ monitors and through direct observation in a laboratory setting, and 94\% agreement in a free-living environment (Kozey-Keadle, Libertine, Lyden, Staudenmayer, \& Freedson, 2011).

Items on sitting behaviours were taken from the SAPAS: "The following 2 questions are about sitting e.g. at work, with friends, travelling, reading, doing hobbies or watching television or reclining at work, at home, getting to and from places, or with friends including time spent [sitting] at a desk, sitting with friends, travelling in car, bus, train, reading, playing cards or watching television; but do not include time spent sleeping. How much time do you usually spend sitting or reclining on a typical day? (recorded as hours and minutes). How often do you take regular breaks (every 15 -20 minutes) when sitting for long periods? Response options: Always; Sometimes; Rarely; Never" (coded 1-4). These items have been included in the 2007, 2010 and 2013 waves of the SAPAS. The first of these questions is from the Global Physical Activity Questionnaire (GPAQ; Bull, Maslin \& Armstrong, 2009), while the second question was designed specifically for the SAPAS.

Time spent sedentary (classified as sitting/lying) per 24 hour period (midnight to midnight) was determined from the $\operatorname{activPAL}^{\circledR}$ output, inclusive of time in bed. Time in bed was estimated based on examination of the 'event' files from the activPAL ${ }^{\circledR}$ in conjunction with self-report, as reported previously (Healy et al., 2008). In brief, approximate times for 'going to bed' and 'getting up' were identified from self-report; the activPAL ${ }^{\circledR}$ 'event' files were used to refine these times based on identification of a change from an upright posture to a prolonged sedentary posture for 'going to bed' time and from a prolonged sedentary posture to an upright posture 
for 'getting up' time. For one participant it was not possible to calculate time in bed from activPAL ${ }^{\circledR}$ output; in this case self-reported time in bed was calculated and used in analyses. As this method of calculating time in bed incorporates a selfreported component, we decided against compromising the objective $24 \mathrm{~h}$ data by subtracting time in bed. Instead, time in bed was controlled for in correlational analyses. Sedentary breaks were defined by the number of times a participant transitioned from a sedentary posture (sitting or lying) to an upright posture (either standing or walking). Daily averages were calculated for sedentary time and the number of breaks in sedentary time. As the principal analytical technique was correlation, a preliminary test, df beta, was performed to identify influential observations in the dataset, resulting in the removal of one office worker from analyses (dfbeta $>2 / n^{-2}$ ).

Anthropometry

Weight was measured to the nearest $0.1 \mathrm{~kg}$ using electronic scales (Tanita BF $679 \mathrm{~W}$ ) and standing height was measured to the nearest one millimetre using a portable stadiometer. Body mass index (BMI) was calculated as weight (kg) divided by height $(\mathrm{m})$ squared.

\section{Education}

The highest level of education was reported from the following options: Still at school; Left after 16 years; Left after 16 years but still studying; Trade/apprenticeship; Certificate/diploma; University degree or higher.

Statistical methods 
Analyses were performed in Stata v11 (StataCorp LP, College Station, TX). Descriptive statistics are presented as mean +/- SD or frequencies of categorical responses. Farmers and office workers were compared using t tests for continuous variables and Chi square for categorical variables. The reliability intra-class correlations (ICCs) for the three measurement days were calculated for total sedentary time. As the validity of self-reported physical activity can vary according to weight status (Warner et al., 2012) and the task of recalling previous behaviours is a cognitive challenge (Baranowski, 1988), relationships between self-reported and objectively measured sedentary time were determined using partial correlation analysis, controlling for BMI and level of education as well as time in bed. Spearman correlations were used to describe the relationships between self-reported and objectively measured number of breaks in sedentary time. All correlational analyses were calculated in the whole sample as well as for farmers and office workers separately. Statistical significance was inferred at $P<0.05$.

Results

Sixty eligible participants volunteered for the study, 30 farmers and 30 office workers. For data to be included in analyses, participants were required to wear the monitor for three complete days (72 hours), and during that time must have engaged in three full days at work. Two participants (one office-worker and one farmer) were excluded from analyses due to non-wear time, resulting in a final sample of 29 farmers and 28 office workers. Reliability ICCs for objectively measured sedentary time were: whole sample, 0.77; farmers, 0.65 ; and office workers, 0.86 .

Eighty nine percent of both office workers and farmers were classified as overweight/obese. Farmers were marginally older than office workers and were significantly less likely to be university educated (see Table 1). Both self-reported and objectively measured sedentary time were significantly lower in farmers; 
farmers spent $44 \%$ of their total work time being sedentary compared with $67 \%$ for office workers. There were no differences between groups in self-reported frequency of breaks in sedentary time or objectively measured daily number of breaks (see Table 1).

A significant correlation between self-reported and objectively measured sedentary time was observed in the whole sample $(r=0.44, p=0.001)$. The correlation among office workers was significant $(r=0.57, p=0.003$; see Figure 1$)$ but not among farmers $(r=-0.08, p=0.68$; see Figure 2).

There were no significant correlations between self-reported and measured number of breaks in sedentary time, for the whole sample (rho $=-0.03, p=0.83$ ), office workers (rho $=0.17, p=0.39$ ) and farmers (rho $=-0.22, p=0.25$ ).

Discussion

This study reports a large correlation, according to the conventions of Cohen (Cohen, 1988), between self-reported and objectively measured sedentary time among rural adult males employed in office-based occupations. However, among farmers in the same rural region, there was no association between self-reported and objectively measured sedentary behaviour. These observations are consistent with another recent validation study of self-reported sedentary behaviour in which accelerometry was used to validate workplace sitting questions adapted from the IPAQ (Clark et al., 2011). Validity coefficients for workplace sitting were determined among three occupation subsets: office workers; call centre workers; and customer service workers. Notably, validity coefficients were significant among those with essentially desk-based roles (office, $r=0.34$ to 0.44 ; call centre, $r=0.13$ to 0.27 ), but non-significant among customer service staff $(r=-0.06$ to -0.02$)$ who typically spend more time standing and walking in their role (Clark et al., 2011). It is feasible that desk-based occupations are relatively highly regimented, with scheduled and 
predictable breaks such as morning tea and lunch. Accordingly, office workers may be better equipped to self-report workplace sitting in the previous day as they can draw upon awareness of their 'typical' work day. On the other hand, farmers' work days are characterised by a wide range of tasks with less continuity or consistency between days, perhaps limiting their ability to recall recent daily patterns. Nevertheless, our results show that farmers' work days still included a substantial amount of total sedentary time, highlighting the importance of objective measures of sedentary time in this group.

While the validity of self-reported frequency of breaks in sitting was relatively poor in the current study, the validity among office workers (rho $=0.17$ ) was higher than among farmers (rho $=-0.22$ ). This is consistent with the observations of Clark et al. (2011) who found a higher correlation between self-reported and accelerometer-derived breaks in workplace sitting among office workers (rho $=0.23$ ) than customer service workers (rho $=-0.05$ ). Again, more frequent and less predictable transitions from sitting to standing in 'active' occupations may limit the ability to describe through self-report a 'typical' daily pattern of interrupting sitting (Clark et al., 2011).

Notably, among office workers but not farmers the three day measurement period was adequate to achieve the accepted reliability ICC of 0.80 for objectively measured physical activity in adults (Tudor-Locke et al., 2005). This is perhaps reflective of the wide variety of often unscheduled work tasks that farmers perform both indoors and outdoors, unlike the more tightly regimented and monotonous time use patterns that are typical of the modern office.

A strength of the current study was the use of posture and postural transitions derived from an inclinometer to validate self-reported sedentary behaviour. While 100 counts per minute $(\mathrm{cpm})$ has been adopted as a cut-point to define sedentary behaviour from accelerometry data (Clark et al., 2011), periods of time $\leq 100 \mathrm{cpm}$ may include standing relatively still which would result in 
overestimation of sedentary time. Furthermore, the utility of the $100 \mathrm{cpm}$ cut point has only been tested in relatively few populations (Matthews et al., 2008). A further strength of the study was the adequate statistical power to detect moderate correlation coefficients in occupation sub-samples (Cohen, 1988).

Several limitations of this study should be acknowledged. Data were collected during one phase of the farming year. While an office worker's postural and activity patterns at work may remain relatively consistent throughout a working year, a farmer's activity may be much higher during sowing and harvesting periods. If validity of self-reported sedentary time is influenced by the amount of workplace sitting, as suggested by this study, the difference in validity of sedentary selfreporting between office workers and farmers may be wider if considered across a whole year. In the current study, office workers engaged in sedentary behaviour for $67 \%$ of their work time, very similar to the proportion of office-based sedentary time (66\%) reported by Brown, Ryde, Gilson, Burton and Brown (2013), but substantially lower than $75 \%$ reported by Thorpe and Dunstan (2009) and $76 \%$ reported by Toomingas, Forsman, Mathiessen, Heiden and Nilsson (2012). If validity of selfreported sitting is associated with the extent to which movement in the workplace is automated and habitual, as the results of this study and the findings of Clark and colleagues (2011) suggest, the validity coefficient for office workers in the current study is limited in its generalizability to other office settings where the proportion of sedentary time is different.

Reactivity may have confounded measurement, whereby participants alter usual sedentary and active patterns as a consequence of being assessed (Dollman et al., 2009). In this study, we attempted to minimise reactivity by fitting the activPAL ${ }^{\circledR}$ on participants the day before recording started. The light weight and unobtrusiveness of the monitor also reduces ongoing awareness of its attachment (Godfrey, Culhane, \& Lyons, 2007) as does the absence of the need to remove and 
reattach the monitor each day. Social desirability bias may also have led to underestimation of sedentary behaviour though self-report (Adams et al., 2005) but it is not possible to quantify the relative impact of these biases on the observed correlations.

The farmers in this sample study were limited to two main agricultural industries, grape-growing $(n=15)$ and dryland farming $(n=14)$. A comparison between these sub-samples showed that the grape-growers spent $48 \%$ of their day being sedentary compared with $41 \%$ among dry-land farmers. While sub-sample sizes are small, this suggests that sedentary behaviours at work may vary with the type of farming and highlights the need to extend the research to include a wider range of primary industries. Also, the study was confined to men in full time employment. Future studies should include women and those in part-time work and domestic/carer roles as well as unemployed and retirees.

Conclusion

While self-reporting of sedentary behaviour is an appealing strategy due to low cost and very low respondent burden, the results of this study suggest it is of limited utility in rural Australians. This particularly applies to the self-report of breaks in sitting time. Among those with irregular work patterns, self-report of sedentary behaviour seems to be of no value. Given the relevance of sedentary behaviour measurement to the public health crisis of escalating chronic disease, better performing self-report instruments need to be developed for population-level monitoring of the distribution of posture across the day. At the same time, technological approaches need to be available at lower cost and higher convenience to support research into patterns and consequences of sedentary behaviour and the effectiveness of interventions to reduce prolonged sitting. 
References

Adams, S.A., Matthews, C.E., Ebbeling, C.B., Moore, C.G., Cunningham, J.E., Fulton, J., \& Hebert, J.R. (2005). The effect of social desirability and social approval on self-reports of physical activity. American Journal of Epidemiology, 161, 389-398.

Australian Bureau of Statistics. (2006a). 2006 Census QuickStats: Riverland (statistical subdivision). Retrieved 1 September 2012, from http://www.censusdata.abs.gov.au/census_services/getproduct/census/2006 /quickstat/42005?opendocument\&navpos=220.

Australian Bureau of Statistics. (2006b). Statistical Geography Volume 1 - Australian Standard Geographical Classification (ASGC) (cat. no. 1216.0). Canberra: Australian Bureau of Statistics.

Australian Institute of Health and Welfare. (2010). Australia's Health 2010. Canberra: Australian Institute of Health and Welfare.

Baranowski, T. (1988). Validity and reliability of self report measures of physical activity: an information-processing perspective. Research Quarterly for Exercise \& Sport, 59, 314-327.

Brown, H.E., Ryde, G.C., Gilson, N.D., Burton, N.W., \& Brown, W.J. (2013).

Objectively measured sedentary behaviour and physical activity in office employees: relationships with presenteeism. Journal of Occupational and Environmental Medicine, 55, 945-953.

Bull, F.C., Maslin, T.S., \& Armstrong, T. (2009). Global physical activity questionnaire (GPAQ): nine country reliability and validity study. Journal of Physical Activity and Health, 6, 790-804.

Carnethon, M., Whitsel, L.P., Franklin, B.A., Kris-Etherton, P., Milani, R., Pratt, C.A., \& Wagner, G.R. (2009). Worksite wellness programs for cardiovascular 
disease prevention: a policy statement from the American Heart Association. Circulation, 120, 1725-1741.

Cohen, J. (1988). Statistical power analysis for the behaviour sciences: $2^{\text {nd }}$ edition. Hillsdale, NJ: Erlbaum.

Clark, B.K., Thorp, A.A., Winkler, E.A., Gardiner, P.A., Healy, G.N., Owen, N., \& Dunstan, D.W. (2011). Validity of self-reported measures of workplace sitting time and breaks in sitting time. Medicine \& Science in Sports \& Exercise, 43, 1907-1912.

Dollman, J., Okely, A.D., Hardy, L., Timperio, A., Salmon, J., \& Hills, A.P. (2009). A hitchhiker's guide to assessing young people's physical activity: deciding what method to use. Journal of Science \& Medicine in Sport, 12, 518-525.

Gill, T., Fullerton, S., \& Taylor, A. (2008). Physical activity among South Australian adults: September 2007. Adelaide SA: Population Research and Outcome Studies Unit, South Australian Department of Health.

Godfrey, A., Culhane, K.M., \& Lyons, G.M. (2007). Comparison of the performance of the activPAL professional physical activity logger to a discrete accelerometer-based activity monitor. Medical Engineering \& Physics, 29, $930-934$

Grant, P.M., Ryan, C.G., Tigbe, W.W., \& Granat, M.H. (2006). The validation of a novel activity monitor in the measurement of posture and motion during everyday activities. British Journal of Sports Medicine, 40, 992-997.

Hart, T.L., McClain, J.J., \& Tudor-Locke, C. (2011). Controlled and free-living evaluation of objective measures of sedentary and active behaviors. Journal of Physical Activity \& Health, 8, 848-857. 
Healy, G.N., Dunstan, D.W., Salmon, J., Cerin, E., Shaw, J.E., Zimmet, P.Z., \& Owen, N. (2008). Breaks in sedentary time: beneficial associations with metabolic risk. Diabetes Care, 31, 661-666.

Kozey-Keadle, S., Libertine, A., Lyden, K., Staudenmayer, J., \& Freedson, P.S. (2011). Validation of wearable monitors for assessing sedentary behavior. Medicine \& Science in Sports \& Exercise, 43, 1561-1567.

Matthews, C.E., Chen, K.Y., Freedson, P.S., Buchowski, M.S., Beech, B.M., Pate, R.R., \& Troiano, R.P. (2008). Amount of time spent in sedentary behaviors in the United States, 2003-2004. American Journal of Epidemiology, 167, 875881.

Pontt, J.L., Rowlands, A.V., \& Dollman, J. (2015). A comparison of sedentary behaviours among rural men working in offices and on farms. Australian Journal of Rural Health, 23, 74-79.

Population Research and Outcome Studies Unit. (2010). The health status of people living in the South Australian health regions. Adelaide, SA: Population Research and Outcome Studies Unit, South Australian Department of Health.

Thorpe, A., \& Dunstan, D. (2009). Stand up Australia: sedentary behaviour in workers: August 2009. Queensland: Baker IDI Heart and Diabetes Institute and the Cancer Prevention Research Centre, University of Queensland.

Toomingas, A., Forsman, M., Mathiassen, S.E., Heiden, M., \& Nilsson, T. (2012). Variation between seated and standing/walking postures among male and female call centre operators. BMC Public Health, 12, 154-168.

Tudor-Locke, C., Burkett, L., Reis, J.P., Ainsworth, B.E., Macera, C.A., \& Wilson, D.K. (2005). How many days of pedometer monitoring predict weekly physical activity in adults? Preventive Medicine, 40, 293-298. 
van Uffelen, J.G., Wong, J., Chau, J.Y., van der Ploeg, H.P., Riphagen, I., Gilson, N.D., Brown, W.J. (2010). Occupational sitting and health risks: a systematic review. American Journal of Preventive Medicine, 39, 379-388.

Warner, E.T., Wolin, K.Y., Duncan, D.T., Heil, D.P., Askew, S., \& Bennett, G.G. (2012). Differential accuracy of physical activity self-report by weight status. American Journal of Health Behavior, 36, 168-178. 
Table 1 Demographic and descriptive statistics for the whole sample and separately for office workers and farmers

\begin{tabular}{|c|c|c|c|}
\hline Variables & $\begin{array}{l}\text { All } \\
(n=58)\end{array}$ & $\begin{array}{l}\text { Office worker } \\
(n=29)\end{array}$ & $\begin{array}{l}\text { Farmer } \\
(n=29)\end{array}$ \\
\hline $\begin{array}{l}\text { Demographic } \\
\text { variables }\end{array}$ & & & \\
\hline Age (years) & $48.9(9.0)$ & $46.9(8.5)$ & $50.7(9.7)$ \\
\hline BMI $\left(\mathrm{kg} \cdot \mathrm{m}^{-2}\right)$ & $29.13(3.89)$ & $28.39(3.23)$ & $29.87(4.38)$ \\
\hline $\begin{array}{l}\text { Highest education } \\
(\%)\end{array}$ & & & \\
\hline Still at school & 0 & 0 & 0 \\
\hline $\begin{array}{l}\text { Left school before } 16 \\
\text { years }\end{array}$ & 19.0 & 0 & $37.9^{a}$ \\
\hline Left after 16 years & 17.2 & 17.2 & 17.2 \\
\hline Left after 16 years but & 0 & 0 & 0 \\
\hline still studying & & & \\
\hline Trade/apprenticeship & 5.2 & 3.4 & 6.9 \\
\hline Certificate/diploma & 37.9 & 37.9 & 37.9 \\
\hline $\begin{array}{l}\text { University degree or } \\
\text { higher }\end{array}$ & 20.7 & 41.1 & $0^{a}$ \\
\hline $\begin{array}{l}\text { Self-reported } \\
\text { behaviours }\end{array}$ & & & \\
\hline Time in bed $(\mathrm{h})$ & $8.2(1.10)$ & $7.9(1.1)$ & $8.3(0.8)$ \\
\hline
\end{tabular}


(h)

Frequency of breaks

(\%)

\begin{tabular}{|c|c|c|c|}
\hline Always & 12.1 & 20.7 & 3.4 \\
\hline Sometimes & 55.2 & 51.7 & 58.6 \\
\hline Rarely & 27.6 & 20.7 & 34.5 \\
\hline Never & 5.2 & 6.9 & 3.4 \\
\hline \multicolumn{4}{|l|}{ Objectively } \\
\hline \multicolumn{4}{|l|}{ measured } \\
\hline \multicolumn{4}{|l|}{ behaviours } \\
\hline Sitting/lying (h) & $17.2(1.7)$ & $17.9(1.4)$ & $16.5(1.8)^{a}$ \\
\hline \multicolumn{4}{|l|}{ (including time in bed) } \\
\hline Break number (per & $71.2(20.3)$ & $70.2(16.7)$ & 73.9 \\
\hline
\end{tabular}

Note: data presented as means (SD) or percentages; ${ }^{a} P<0.05$ 


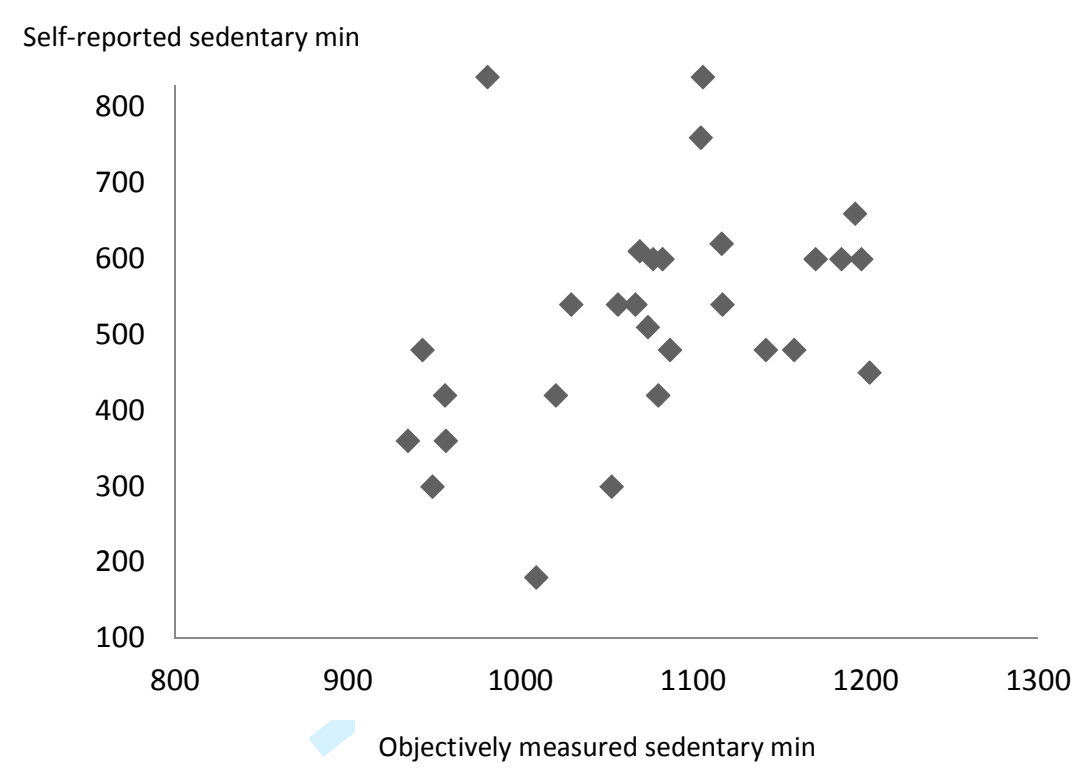

Figure 1: Scattergram of objectively measured and self-reported sedentary time in rural male office workers

URL: http://mc.manuscriptcentral.com/rjsp 
1

2

3

4

5

6

7

8

9

10

11

12

13

14

15

16

17

18

19

20

21

22

23

24

25

26

27

28

29

30

31

32

33

34

35

36

37

38

39

40

41

42

43

44

45

46

47

48

49

50

51

52

53

54

55

56

57

58

59

60
Self-reported sedentary $\mathrm{min}$

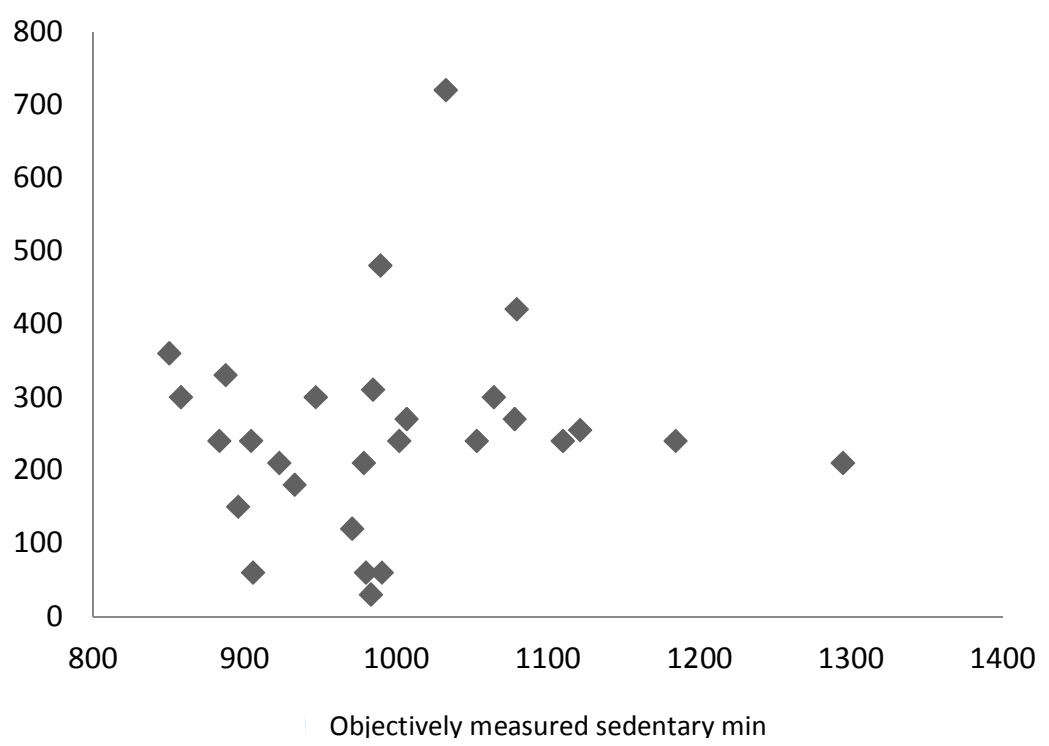

Figure 2: Scattergram of objectively measured and self-reported sedentary time in male farmers

URL: http://mc.manuscriptcentral.com/rjsp 